\title{
Erratum zu: Bedeutung des Wirtschaftsrechts für die volkswirtschaftliche Entwicklung
}

\section{Erratum zu:}

\section{A. Wulf, Bedeutung des Wirtschaftsrechts für die volkswirtscha- ftliche Entwicklung, https://doi.org/10.1007/978-3-658-22034-1}

Folgende Seiten im Buch wurden aktualisiert:

- Text der Danksagung - S. V-VI

- Darstellung des Inhaltsverzeichnisses - S. VII-XIV

- Verzeichnis der Vorveröffentlichungen S. XV und XVII wurde ergänzt

- Benennung der Autorenschaft für Teil A - Seite 11

- Benennung der Autorenschaft für Teil B - Seite 87

Die aktualisierte Originalversion des Kapitels kann hier abgerufen werden https://doi.org/10.1007/978-3-658-22034-1_2

https://doi.org/10.1007/978-3-658-22034-1_3

(C) Springer Fachmedien Wiesbaden GmbH, ein Teil von Springer Nature 2018 